Adjusted analyses did not show an increased risk for gestational diabetes, small for gestational age (SGA) and low birth weight (LBW) in PsA patients (table 2). However, estimates for other obstetric outcomes diverged.

Conclusion: Individual studies showed a trend towards increased disease activity after pregnancy in PsA patients but due to the heterogeneity of the instruments used, it is difficult to summarise the single results. No signal for specific adverse pregnancy outcomes was identified. However, a higher risk for (pre)eclampsia, elective caesarean section and preterm birth cannot be ruled out. Differences in studies (e.g. primary vs secondary data) limit statements on obstetric outcomes. Harmonization of approaches and instruments is crucial in order to enable future joint data analyses and meta-analyses. In particular, a standardised instrument for assessing disease activity of PsA that takes into account the particularities of pregnancy is needed.

Funding: This work was supported by a research grant from FOREUM Foundation for Research in Rheumatology.

Disclosure of Interests: Yvette Meißner Speakers bureau: Pfizer, Tatjana Rudi: None declared, Rebecca Fischer-Betz Consultant of: UCB, Speakers bureau: Abbvie, Amgen, Biogen, BMS, Celgene, Chugai, GSK, Janssen, Lilly, Medac, MSD, Novartis, Roche, UCB, Pfizer., Anja Strangfeld Speakers bureau: AbbVie, BMS, Pfizer, Roche, Sanofi-Aventis

DOI: 10.1136/annrheumdis-2020-eular.3076

\section{AB0805 $\quad$ PREMATURE ATHEROSCLEROSIS IN PSORIATIC ARTHRITIS (PSA) PATIENTS AND ITS POSSIBLE ASSOCIATION WITH INSULIN RESISTANCE \& SERUM LEPTIN LEVEL}

N. Mohannad $^{1}$, M. Zehairy ${ }^{2}$, M. Darwish ${ }^{3} .{ }^{1}$ Faculty of Medicine, Alexandria University Hospitals, Internal Medicine Department, Rheumatology Unit, Alexandria, Egypt; ${ }^{2}$ Faculty of Medicine, Alexandria University, internal Medicine Department, Rheumatology Unit, Alexandria, Egypt; ${ }^{3}$ Alexandria Armed Force Hospital, Alexandria, Egypt

Background: PsA is a heterogeneous inflammatory arthritis. Patients (pts) with PsA suffer from associated cardiovascular disease, obesity, metabolic syndrome, diabetes (DM), osteoporosis. In psoriasis, leptin has been shown to stimulate keratinocyte proliferation, expression of adhesion molecules and angiogenesis.

Objectives: To detect the presence of premature atherosclerosis in PsA pts, measure HOMA-IR as a reflection of insulin resistance (IR) and serum leptin (LEP) level \& to detect their association with the presence of premature atherosclerosis in PsA pts.

Methods: 45 PsA pts (classified according to CASPAR Criteria) \& 45 healthy subjects as controls were included. Pts were subjected to history taking, clinical examination to determine body mass index (BMI), the clinical type of PsA, distribution, involved body surface area (BSA), measuring the Psoriasis Area and Severity Index (PASI) and Disease Activity in PSoriatic Arthritis: DAPSA score. Routine laboratory, fasting insulin (FI), fasting blood glucose (FBG) to calculate HOMA-IR,total cholesterol (TC), HDL, LDL, Triglycerides (TG), serum LEP, carotid Doppler to determine Carotid intima-media thickness (CIMT) \& presence or absence of plaques were done. Exclusion: DM, RA, SLE, smoking, postmenopausal females, HCV infection, morbid obesity

\begin{tabular}{lcc}
\hline CIMT & Person correlation coefficient & p-value \\
\hline BMI & 0.095 & 0.371 \\
Duration of disease (years) & 0.179 & 0.239 \\
BSA score & 0.12 & 0.434 \\
PASI & 0.186 & 0.221 \\
FBG & 0.059 & 0.582 \\
WBC & -0.104 & 0.329 \\
Platelet & 0.022 & 0.835 \\
Hb & -0.106 & 0.319 \\
HDL & 0.505 & $0.000^{\star *}$ \\
LDL & 0.382 & $0.000^{\star *}$ \\
TC & 0.275 & $0.009^{* *}$ \\
Triglyceride & 0.06 & 0.577 \\
SGOT & 0.03 & 0.776 \\
SGPT & 0.033 & 0.754 \\
Serum leptin & 0.537 & $0.0001^{\star *}$ \\
HOMA IR & 0.446 & $0.000^{* *}$ \\
ESR & 0.351 & $0.001^{* *}$ \\
CRP & 0.320 & $0.002^{* *}$ \\
Urea & 0.445 & 0.784 \\
Creatinine & 0.392 & 0.954 \\
Uric acid & 0.034 & 0.748 \\
FI & 0.431 & $0.000^{* *}$ \\
\hline
\end{tabular}

Results: Mean BMI $22.51 \pm 1.69$ and $23.46 \pm 1.82 \mathrm{~kg} / \mathrm{m}^{2}$, no statistical significance $(P=0.205)$

Mean BSA $5.9 \pm 3.1 \%$, DAPSA score $(13.98 \pm 4.7)$, PASI score: $88.9 \%$ (40 pts) had mild to moderate PASI, 5 had severe disease $(8.6 \pm 4.8)$

TC, LDL and TG were higher in pts, while HDL was higher in controls $(P=0.0003$ $0.0001,0.00001 \& 0.05)$.

A significance between 2 groups regarding LEP $(P=0.00001)$, ranging from 2-16.99 $(9.7 \pm 4.5)$ in group I and 1.35-1.78 $(1.6 \pm 0.1) \mu \mathrm{g} / \mathrm{ml}$ in controls. Normal: 2.6-8.35

$\mathrm{FI} \& \mathrm{HOMA} I \mathrm{R}$ were significantly higher in $\mathrm{PsA}$ group $(\mathrm{P}=0.001,0.00001)$

The mean CIMT $1.1 \pm 0.3 \mathrm{~mm}$ and in group II $0.8 \pm 0.1 \mathrm{~mm} .14 \mathrm{pts}(31.1 \%)$ had plaque, while $68.9 \%$ \& all controls had no plaques, with a significance regarding CIMT \& presence of plaques $(P=0.011 \& 0.0041)$.

A positive statistical significance between LEP and dd ( $P=0.001), B S A, P A S I$ and DAPSA ( $P=0.007,0.003,0.001)$ but not with age, BMI $(P=0.98 \& 0.88)$.

There was no statistical significance between LEP and FBG, HbA1C, HOMA IR, FI, CBC ( $P>0.05)$, or between LEP and TC, TG, HDL, LDL $(P=0.438,0.390$, $0.699,0.050)$, liver enzymes, renal functions, ESR and CRP.

There was statistical positive correlation between LEP and CIMT ( $P=0.0001)$, but not with the presence of plaques $(\mathrm{P}=0.846)$

CIMT and other variables: Table 1

DAPSA: there was no statistical significance with TC, HDL, LDL and TG $(P=0.51,0.876,0.717 \& 0.255)$, but a statistically significance with LEP and $\operatorname{CIMT}(p=0.001 \& 0.009)$. Pts with higher score had higher LEP and increased CIMT.

PASI: there was no significance between TC, HDL, LDL, TG $(P=0.724,0.157$, $0.651 \& 0.374)$ or CIMT $(p=0.290)$ in mild-moderate and severe PASI. LEP was significantly higher in severe PASI score $(P=0.001)$

Conclusion: The presence of abnormal lipid profile, IR, increased CIMT, high disease activity and increased LEP may be considered as useful criteria for early recognition and thus prevention of atherosclerosis in PsA pts.

References:

[1] Miller I M, et al. Meta-analysis of psoriasis, cardiovascular disease and associated risk factors. J Am Acad Dermatol 2013

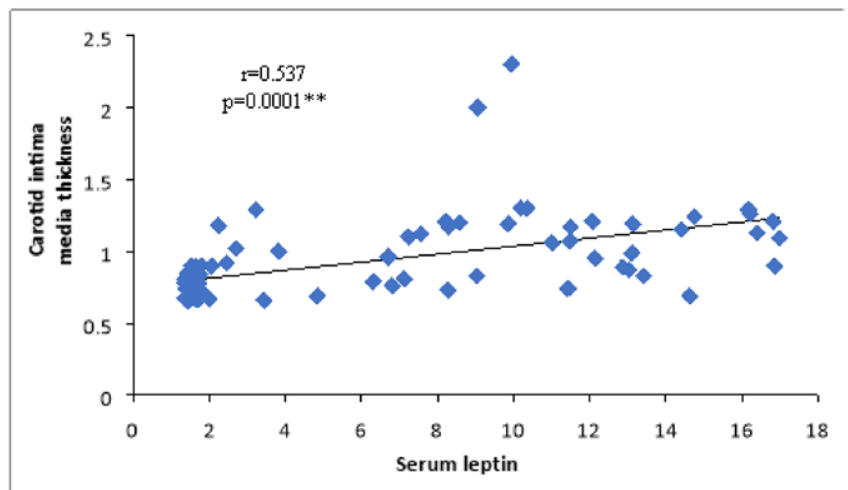

Disclosure of Interests: None declared DOI: 10.1136/annrheumdis-2020-eular.5883

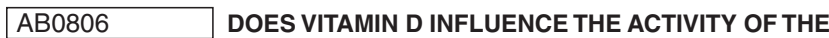 DISEASE IN PATIENTS WITH PSORIATIC ARTHRITIS?}

L. Montolio-Chiva ${ }^{1}$, A. V. Orenes Vera ${ }^{1}$, M. Aguilar-Zamora ${ }^{2}$, C. VergaraDangond $^{3}$, I. Vázquez-Gómez ${ }^{1}$, E. Flores ${ }^{1}$, A. Sendra-García ${ }^{1,4}$,

À. Martínez-Ferrer ${ }^{1}$, E. Valls-Pascual ${ }^{1}$, D. Ybáñez-García ${ }^{1}$, V. Núñez-Monje ${ }^{1}$, I. Torner-Hernández ${ }^{1}$, J. J. Alegre-Sancho ${ }^{1} .{ }^{1}$ Universitary Peset Doctor Hospital, Valencia, Spain; ${ }^{2}$ Sagunto Hospital, Valencia, Spain; ${ }^{3}$ Universitary Infanta Sofía Hospital, Madrid, Spain; ${ }^{4}$ Foundation for the Promotion of Sanitary and Biomedical Research in the Valencian Community (FISABIO), Valencia, Spain

Background: Several studies have shown an inverse relationship between vitamin D levels (25OHD) and disease activity in patients with rheumatoid arthritis (RA). However, the existing data in patients with psoriatic arthritis (PsA) are poor, and they use the DAS28 index as a peripheral joint activity marker by extrapolation with RA.

Objectives: To analyze the relationship between $250 \mathrm{HD}$ levels, disease activity and functional capacity in patients with PsA.

Methods: Transversal, observational, descriptive study. We included PsA patients with peripheral joint involvement. We collected demographic variables (gender, age), clinical variables [follow-up, received treatments, TJC 
(68), SJC (68), VAS] and analytical variables (25OHD, CRP, ESR). We used Disease activity in psoriatic arthritis (DAPSA) score to measure disease activity, and the Health assessment questionnaire (HAQ) to determine functional capacity. Levels of $25 \mathrm{OHD}<20 \mathrm{ng} / \mathrm{ml}$ and between $20-30 \mathrm{ng} / \mathrm{ml}$ were considered deficient and insufficient, respectively. Statistical analysis was made with SPSS 22.0. The descriptive analysis results were expressed as percentage and mean \pm SD. We used Pearson's correlation to assess the association between quantitative variables and $\mathrm{T}$ test to compare means between dichotomous variables.

Results: 125 patients were included, the majority women $(60.8 \%)$, with an average age of 55.4 (SD 12.2) years. The average follow-up was 75.5 (SD 68.3) months. $97.6 \%$ of patients had received DMARDs and $40.8 \%$ biologics, and almost half of the patients (42.7\%) took calcium and $250 \mathrm{HD}$ supplements. The average value of $250 \mathrm{HD}$ was 27.1 (SD 12.1) $\mathrm{ng} / \mathrm{ml}$, with $30 \%$ of patients having $25 \mathrm{OHD}$ deficit and $63.3 \%$ insufficiency. The majority of patients had an acceptable disease control, with a mean DAPSA of 10.5 (SD 7,9); and mean of CRP, ESR, TJC and SJC was 6.1 (SD 3.7) mg/l, 10.2 (SD 9.9) mm/h, 1.3 (SD 2.5) and 0.7 (SD 2.1), respectively. The average value of $\mathrm{HAQ}$ was 0.6 (SD 0.7 ). We observed an inverse correlation between 25OHD levels and joint counts, TJC $(p=0.02)$ and SJC $(p=0.03)$. On the other hand, patients with hypovitaminosis $D$ presented a tendency to get higher scores in DAPSA index $(P=0.07)$. We do not observe any relationship between $250 \mathrm{HD}$ and $\mathrm{HAQ}$.

Conclusion: As can be seen in our sample, low values of $25 \mathrm{OHD}$ are related to increased disease activity in patients with PsA.

Disclosure of Interests: L Montolio-Chiva: None declared, Ana V Orenes Vera: None declared, Marta Aguilar-Zamora: None declared, C Vergara-Dangond: None declared, I Vázquez-Gómez: None declared, Eduardo Flores: None declared, A Sendra-García: None declared, À Martínez-Ferrer: None declared, Elia Valls-Pascual Grant/research support from: Roche, Novartis, and AbbVie, Speakers bureau: AbbVie, Lilly, Pfizer, MSD, Novartis, Janssen, Bristol Myers Squibb, UCB Pharma, D Ybáñez-García Speakers bureau: Lilly, Roche, Sanofi, V Núñez-Monje: None declared, I Torner-Hernández: None declared, Juanjo J Alegre-Sancho Consultant of: UCB, Roche, Sanofi, Boehringer, Celltrion, Paid instructor for: GSK, Speakers bureau: MSD, GSK, Lilly, Sanofi, Roche, UCB, Actelion, Pfizer, Abbvie, Novartis

DOI: 10.1136/annrheumdis-2020-eular.4625

\section{AB0807 \\ VITAMIN D ROLE IN VASCULAR DAMAGE PROGRESSION IN PATIENTS WITH PSORIATIC} ARTHRITIS

L. Montolio-Chiva ${ }^{1}$, M. Robustillo-Villarino ${ }^{2}$, A. V. Orenes Vera ${ }^{1}$, M. AguilarZamora $^{3}$, C. Vergara-Dangond ${ }^{4}$, I. Vázquez-Gómez ${ }^{1}$, E. Flores ${ }^{1}$, A. SendraGarcía $^{1,5}$, À. Martínez-Ferrer ${ }^{1}$, E. Valls-Pascual ${ }^{1}$, D. Ybáñez-García ${ }^{1}$, V. Núñez-Monje ${ }^{1}$, I. Torner-Hernández ${ }^{1}$, J. J. Alegre-Sancho ${ }^{1} .{ }^{1}$ Universitary Peset Doctor Hospital, Valencia, Spain; ${ }^{2}$ Universitary La Plana Hospital, Castellón, Spain; ${ }^{3}$ Sagunto Hospital, Valencia, Spain; ${ }^{4}$ Universitary Infanta Sofía Hospital, Madrid, Spain; ${ }^{5}$ Foundation for the Promotion of Sanitary and Biomedical Research in the Valencian Community (FISABIO), Valencia, Spain

Background: Psoriatic arthritis (PsA) is associated with insufficent levels of vita$\min \mathrm{D}(25 \mathrm{OHD})$ and an increased cardiovascular risk. Several studies, have shown an inverse relationship between $250 \mathrm{HD}$ levels and cardiovascular damage.

Objectives: To study the relationship between $250 \mathrm{HD}$ and vascular damage, as well as its possible influence on its progression, in patients with PsA.

Methods: Pre-post longitudinal study with analytical components. PsA patients with peripheral joint involvement were included. Demographic (sex, age), clinical [follow-up time, DAPSA, current treatment, body mass index (BMI), classic vascular risk factors, vascular events] and analytical variables [atherogenic index, glomerular filtration (GF-MDRD), glycosylated hemoglobin (HbA1c), CRP, ESR, 25OHD] were collected. We considered deficient level of $250 \mathrm{HD}<20 \mathrm{ng} / \mathrm{ml}$ and insufficient $<30 \mathrm{ng} / \mathrm{ml}$. Basal vascular risk was estimated through SCORE tool. Extracranial carotid artery was explored with an Esaote MyLab70XVG ultrasound with linear probe $(7-12 \mathrm{mHz})$ and an automated program that measures intima media thickness (IMT) by radiofrequency, and the presence of atheroma plaques was evaluated following Mannheim consensus. Pulse wave velocity (PWV) was measured through Mobil o graph® dispositive. IMT $\geq 900 \mu$ and PWV $\geq$ $10 \mathrm{~m} / \mathrm{s}$ were considered as pathological values. We repeat vascular study 3 years later. Vascular damage progression was defined as the appearance of atheroma plaques during the follow-up and/or an increase in their number. Statistical analysis was performed using SPSS 22.0 program.

Results: 78 patients were included. Eighteen patients were excluded due to high vascular risk [previous event, diabetes type II or type I with target organ injury and/or GF-MDRD $<60 \mathrm{ml} / \mathrm{min}$ ]. $57.5 \%$ were women with a mean age of 54.2 (SD
10.9) years. The mean follow-up time was 96.8 (SD 163.6) months and mean DAPSA was 10.2 (SD 8.3). $96.2 \%$ of patients had received DMARDs and $42.3 \%$ biologicals, and $42.3 \%$ took calcium and $250 \mathrm{HD}$ supplements. Mean BMI was 27.5 (SD 4.7 ) kg/m². 42.3\% had tobacco exposure, $29.5 \%$ were hypertensive and $32 \%$ dyslipidemic. Mean SCORE was 1.6 (SD 1.8) and mean 25OHD was 27.6 (DSD 11.6) ng/ml. 28.2\% patients had 25OHD deficit and $60.3 \%$ insufficiency. At the beginning, $32.1 \%$ of patients had atheromatous plaques with a number of plaques around 1.7 (SD 1.2), and $6.7 \%$ and $19.7 \%$ had a pathological IMT or PWV, respectively. Baseline, we had not observed any association between $25 \mathrm{OHD}$ and the presence of atheroma plaques, IMT or PWV. Three years later we detected progression of vascular damage in $31.2 \%$ patients. In these patients, the existence of hypovitaminosis D was associate with the appearance of atheroma plaques $(p=0.043)$. This association desappeared in the multivariate analysis, in which only the CRP influenced the appearance of atherome plaques (OR: 1.4, IC 95\% 1.04-1.98, $\mathrm{p}=0.025$ ).

Conclusion: Low $25 \mathrm{OHD}$ levels are not related to vascular damage or influence a posible progression of it in our serie. As might be expected, the progression of vascular damage depends on the inflammatory load in these patients.

Disclosure of Interests: L Montolio-Chiva: None declared, M Robustillo-Villarino: None declared, Ana V Orenes Vera: None declared, Marta Aguilar-Zamora: None declared, C Vergara-Dangond: None declared, I Vázquez-Gómez: None declared, Eduardo Flores: None declared, A Sendra-García: None declared, À Martínez-Ferrer: None declared, Elia Valls-Pascual Grant/research support from: Roche, Novartis, and AbbVie, Speakers bureau: AbbVie, Lilly, Pfizer, MSD, Novartis, Janssen, Bristol Myers Squibb, UCB Pharma, D Ybáñez-García Speakers bureau: Lilly, Roche, Sanofi, V Núñez-Monje: None declared, I Torner-Hernández: None declared, Juanjo J Alegre-Sancho Consultant of: UCB, Roche, Sanofi, Boehringer, Celltrion, Paid instructor for: GSK, Speakers bureau: MSD, GSK, Lilly, Sanofi, Roche, UCB, Actelion, Pfizer, Abbvie, Novartis DOI: 10.1136/annrheumdis-2020-eular.4583

\section{AB0808 \\ IMPLEMENTING IPAD-BASED ASSESSMENTS TO IMPROVE PERFORMANCE IN A PSORIATIC ARTHRITIS CLINIC AT A DISTRICT GENERAL HOSPITAL}

S. Mukherjee $^{1}$, B. Quilty ${ }^{1}$, H. Burstow ${ }^{1}$, K. Hennessy ${ }^{1} .{ }^{1}$ Christchurch Hospital, Rheumatology Department, Christchurch, United Kingdom

Background: Psoriatic Arthritis (PsA) is a complex disease with profound physical and psychosocial effects. The core domain set for this condition was updated by the Group for Research and Assessment of Psoriasis and Psoriatic Arthritis (GRAPPA)-Outcome Measures in Rheumatology (OMERACT) PsA working group in $2016^{1}$ and the TICOPA (TIght COntrol of Psoriatic Arthritis) study suggested that adopting a 'treat-to-target' approach aiming for Minimal Disease Activity (MDA) could result in better clinical outcomes ${ }^{2}$.

Objectives: To improve assessment of all the core domains of PsA during clinic appointments and aim to treat these patients using a 'treat-to-target' approach to improve clinical outcomes.

Methods: We were able to confirm through a retrospective baseline audit that all core domains of PsA were not being fully addressed in our general rheumatology clinics. A dedicated weekly PsA clinic was then set up at our district genera hospital. Subsequently, iPads incorporated with GRAPPA App were implemented in these clinics to facilitate multi-domain assessments aiming for MDA. This was supported by a Health Education England (Wessex) Quality Improvement Fellowship that involved rheumatology and dermatology team members working in close collaboration. We then carried out a re-audit to assess our performance. Additionally we set up quarterly combined Rheumatology and Dermatology clinics for patients with severe joint and skin involvement. We also conducted a baseline survey by asking patients for their opinion about the 'setting up of the dedicated PsA service', the 'quarterly combined clinics' and the 'use of iPadbased assessments'. We asked them to score each of these on a scale of 0 to 10 , with 0 being 'very negative' and 10 'very positive'.

Results: We had pragmatically set a standard of $75 \%$ for our baseline audit but we found an overall compliance of only $27.4 \%$. There was also a wide variation between different domains with a compliance of even $0 \%$ for some. Domains that are not assessed are unlikely to be fully taken into account when deciding about treatment. The re-audit following the implementation of iPad-based assessments in dedicated PsA clinics showed a significant improvement in each of the domains and the overall compliance went up to $97.9 \%$ (Table 1). The patient survey findings were also excellent with mean scores of 9.5, 9.0 and 9.5 respectively for the three items (Figure 1). 